\title{
ROLE OF CORTICAL MASTOIDECTOMY IN MYRINGOPLASTY: A CLINICAL STUDY
}

\author{
D. Ranganath Swamy1, T. Shankar², Manish Kumar ${ }^{3}$
}

${ }^{1}$ Assistant Professor, Department of ENT, Osmania Medical College/Govt. ENT Hospital, Koti, Hyderabad.

${ }^{2}$ Professor, Department of ENT, Osmania Medical College/Govt. ENT Hospital, Koti, Hyderabad.

${ }^{3}$ Assistant Professor, Department of ENT, Osmania Medical College/Govt. ENT Hospital, Koti, Hyderabad.

\begin{tabular}{l}
\hline ABSTRACT \\
\hline BACKGROUND \\
Chronic Suppurative Otitis Media (CSOM) is a chronic inflammatory process of mucoperiosteal lining of middle ear cleft effect of \\
simple mastoidectomy on patients without evidence of active disease remains highly debated and unproven.
\end{tabular}

\section{OBJECTIVE}

To evaluate the efficiency and role of cortical mastoidectomy in patients with CSOM (safe type) in wet as well as in dry ears.

\section{STUDY DESIGN}

Retrospective study.

\section{METHODS}

Data were collected from the patients operated for myringoplasty with or without cortical mastoidectomy. The study was carried out on a total no. of 156 cases in the total period of 04 years with 06 months follow-up; outcome is evaluated in terms of graft lateralization, rejection and change in $\mathrm{AB}$ gap and achieving dry ear.

\section{RESULTS}

In this study the overall success rate was (94.2), it was higher in dry ear (90.5) as compared to wet ear (86.4).

\section{CONCLUSION}

In both myringoplasty alone or with simple mastoidectomy, failure rates were higher in wet ear as compared to dry ear; however, odds of failure in wet ear cases were higher in myringoplasty alone done as compared to myringoplasty with simple mastoidectomy.

\section{KEYWORDS}

Cortical mastoidectomy, CSOM, Myringoplasty, Ear discharge, Audiogram.

HOW TO CITE THIS ARTICLE: Swamy DR, Shankar T, Kumar M. Role of cortical mastoidectomy in myringoplasty: a clinical study. J. Evolution Med. Dent. Sci. 2016;5(55):3756-3759, DOI: 10.14260/jemds/2016/860

\section{INTRODUCTION}

CSOM is an inflammatory process of the mucoperiosteal lining of the middle ear cleft. It is characterized by thickening of mucous membrane owing to sub-mucosal fibrosis, oedema and infiltration with inflammatory cells. Tympanic membrane perforation is usually a consequence of chronic ear disease, pressure effects, trauma, burns, scalds, out of this CSOM is the most common cause, $6 \%$ of Indian population suffers from chronic ear disease.(1)

Financial or Other, Competing Interest: None.

Submission 02-06-2016, Peer Review 29-06-2016,

Acceptance 04-07-2016, Published 09-07-2016.

Corresponding Author:

Dr. T. Shankar.

Flat No. 401, Plot No. 59 \& 62

GK Rishitha Mari Gold Apts,

Hasthinapuri Colony, Sainikpuri,

Secunderabad - 94

E-mail: drshankar_ms@yahoo.com

DOI: $10.14260 / \mathrm{jemds} / 2016 / 860$

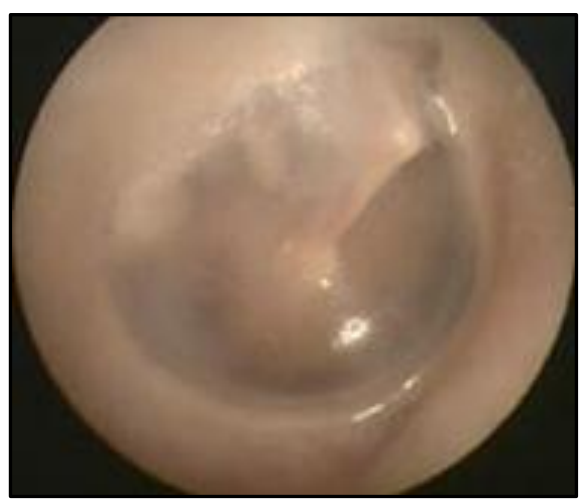

Fig. 1: Normal Tympanic Membrane

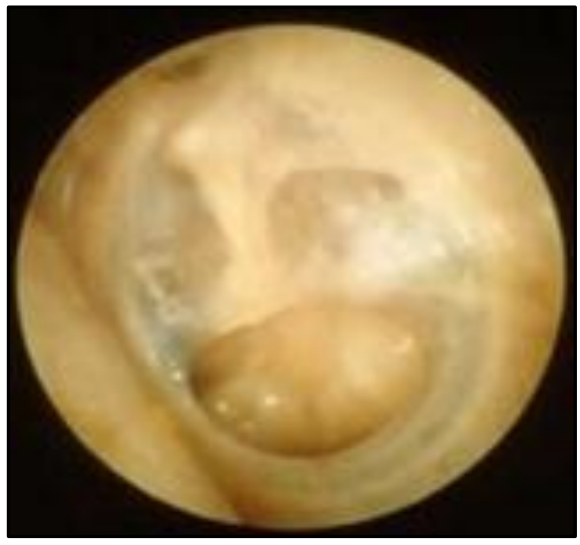

Fig. 2: Central Perforation 
Myringoplasty is a surgery designed to close tympanic membrane perforation. In tympanic membrane perforation two aims should be fulfilled, first one is closure of perforation and second aim is to obtain a new tympanic membrane with acoustic qualities similar to those of a normal tympanic membrane.(2) The first milestone is reconstruction of tympanic membrane; attempts at reconstruction may seem futile as long as the inflammation in and around the middle ear cleft is lurking. In this context simple mastoidectomy seems to be an integral part of tympanoplasty.(3) The effect of cortical mastoidectomy on patients with inactive CSOM remains debated and unproven.(4), but in cases with active disease mastoidectomy has been shown to have significantly better outcome to reduce the postoperative complications.(5) likely injury to the dura, incus, sigmoid sinus and facial nerve.(6)

The aim of the present study was carried out to evaluate the efficacy and role of simple mastoidectomy, in patients with CSOM (Safe type) in relation to success rate and postoperative complications in-active and in-active type of CSOM, suitability of cortical mastoidectomy in patients undergoing myringoplasty.

\section{METHODS AND MATERIALS}

Data for the study was collected from the patients who have undergone myringoplasty-safe type with or without cortical mastoidectomy in the Department of ENT at Osmania Medical College/Govt. ENT Hospital, Hyderabad, for period of 04 years from January 2012 to January 2016. The study was carried out on a total no. of 156 patients who have undergone myringoplasty; all cases were followed up to 06 months postoperatively. The subjects were allocated to one of the two groups as follows depending on symptoms.

Group I ( $n=78$ ) patients of CSOM (Safe type), who were treated with myringoplasty alone.

Group II (n=78) patients of CSOM (Safe type), who were treated with myringoplasty with cortical mastoidectomy.

\section{Inclusion Criteria}

1. Age patients from 14-54 years.

2. Central perforation-Dry and Wet.

3. Gender-both male and female.

4. CSOM-Safe ear with pure conductive hearing loss.

5. Patients with good Eustachian tube function.

6. No disease in the Mastoid.

\section{Exclusion Criteria}

1. Patient below 14 years and above 54 years.

2. Those having sensorineural hearing loss or mixed hearing loss.

3. Patient with cholesteatoma or granulations.

4. Tympanosclerosis cases.

5. Previous mastoid surgery.

6. Uncontrolled systemic diseases.

\section{PROCEDURE}

A predesigned proforma was used to record the relevant information from the individual patients selected with inclusion and exclusion criteria. A detailed history and clinical examination was done with all necessary investigations (PTA, X-ray mastoid, EUM and DNE). Hearing results were assessed by comparing pre-operative and post-operative pure tone, averages, over the $0.5 / 1 / 2 / 4 \mathrm{KH} 2$ frequencies as well as closure of the air bone gap.

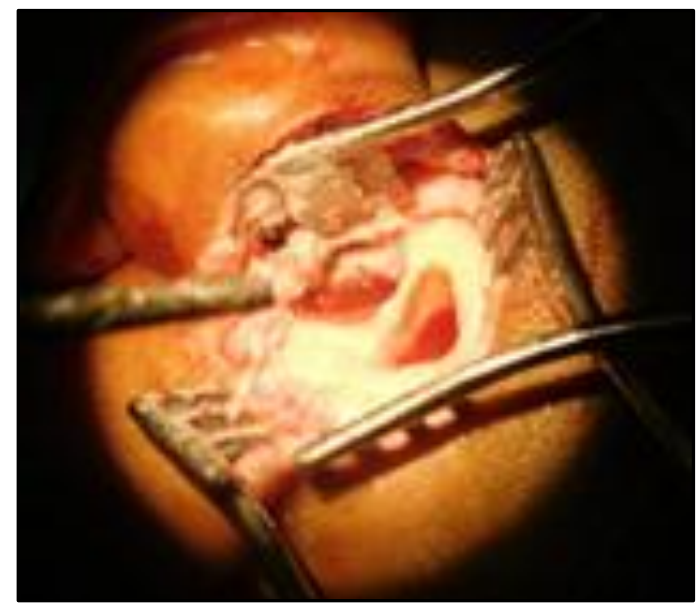

Fig. 3: Cortical Mastoidectomy + Myringoplasty

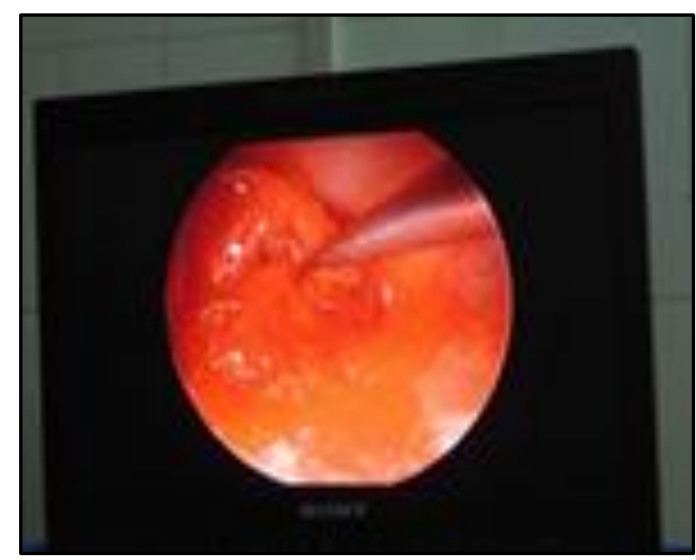

Fig. 4: Post-Op Myringoplasty

\section{Surgical Procedure}

All 156 cases were operated by corresponding author, under local anaesthesia. Group - I. 78 patients were operated through post-aural approach. Myringoplasty was done by underlay technique by using temporalis fascia graft. Patients were followed up to 06 months post-operatively. Assessment of graft uptake, dryness and good hearing improvement was considered if there is no residual perforation seen after the end of 06 months (Follow-up period). Group II: 78 patients had undergone myringoplasty with cortical mastoidectomy through post-aural approach. Postoperative follow-up was performed at the end of $4^{\text {th }}$ week, $14^{\text {th }}$ week and $24^{\text {th }}$ week.

\section{Statistical Analysis}

The statistical analysis was done using SPSS (Statistical Package for Social Sciences) version 21 statistical analysis software in mean+SD and Number (\%). The data was summarized using mean and standard deviation for quantitative variables and frequency and percentage for qualitative ones. Comparison and percentage for qualitative ones between two groups was performed using independent sample t-test for quantitative variables and chi-square test for qualitative ones, paired t-test was conducted to signify the changes in the related quantitative measurement (Air-bone gap).

\section{RESULTS}

The study included 156 patients who were divided randomly into two groups, Group I (n-78) - Myringoplasty alone, where 
48 patients were males and 30 were females. Group II (n-78) Myringoplasty with cortical mastoidectomy done where 46 patients were males and 32 patients were females. Most of the patients were in the age group of 14-54 years, the youngest patient was found to be 14 years old and oldest 50 years. All patients in both groups were followed up to 6 months and statistical analysis was made. The most common presenting symptoms of these patients were hearing loss and ear discharge.

\section{Graft Uptake}

Graft uptake success rates were $93 \%$ in group I where only myringoplasty was done; all the patients were followed up to 6 months, in 68 patients total graft was taken up, 4 cases developed infection and re-perforations within first 2 months in this group, 6 patients were noticed graft failure due to medialisation and improper tugging of the graft. In group-II patients where cortical mastoidectomy was done along with myringoplasty to clear the infection from mastoid and aditus patency was re-established by cleaning the oedematous mucosa and granulations. The graft take up were $92 \%$. There was no statistically significant difference between group I and group II.

\section{Dry Ear}

Dry ears - 6 months post-operatively $88 \%$ in group I patients and $94 \%$ in group II with myringoplasty and cortical mastoidectomy. There was slightly more dry ear achieved in group II.

\section{Air Bone Gap}

Average A-B gap pre-operative was $23.1 \# 83$ in group I, whereas it was 24.2\#8.6 in group II. Average A-B gap 6 months post-operative, in group I was 20.4\#9.2, whereas it was $22.1+8.4$. There was no statistically significant difference regarding A-B gap difference pre- and post-operatively between group I and group II.

\section{DISCUSSION}

CSOM represents the most common disease of the middle ear cleft, myringoplasty with or without cortical mastoidectomy is performed to eradicate the disease in middle ear and reconstruct the conductive hearing mechanism. Cortical mastoidectomy with myringoplasty in cases of active CSOM is performed to clear the mastoid reservoir of infection, but its role in inactive and quiescent disease is questionable. Hence, the present study was carried out with an aim to evaluate the efficiency and role of cortical mastoidectomy in CSOM (Safe type) patients.

Myringoplasty is a surgical procedure in which the reconstructive procedure is the repair of tympanic membrane perforation; in this the ossicular chain is intact and mobile and there is no middle ear infection. Myringoplasty was first described by Lonis Petit in the 1700's, the cortical mastoidectomy was popularized by William House. This procedure attempted to avoid the common complications with radical mastoidectomy and modified radical mastoidectomy.(7) There are a number of studies in the literature highlighting the disadvantages and advantages of performing cortical mastoidectomy in the surgical treatment of safe-type of CSOM. Mastoidectomy is one of the most common otological surgery performed today.
In the present study, the cases selected were between 1454 years, patients aged between 18-30 years were more in the study group; 82 patients (54\%), 36 patients(23\%) were found in age group of 32-41 years; 20 patients $(12.8 \%)$ and 18 patients $(10.2 \%)$ were in $43-54$ years. In a study conducted by Lasisi and Afolab.(8) the majority of patients were aged 23-36 years, which was in concurrence with present study.

The results of present study is also consistent with the study of Charan et al( ${ }^{(9)}$ where success rate of myringoplasty without mastoidectomy was reported $93.33 \%$, whereas in this study it is $94.2 \%$, similarly the results of myringoplasty with mastoidectomy reported to be $97.5 \%$, whereas the present statistically is $95 \%$. Kaur.(10) reported the success rate for myringoplasty with or without mastoidectomy respectively were $88 \%$ and $76 \%$; they also concluded that combining cortical mastoidectomy with tympanoplasty would not give additional benefits in terms of hearing improvement, disease clearance and graft uptake. In 2012 Albu et al(11) found that cortical mastoidectomy offers no additional benefit regarding hearing improvement over myringoplasty. In study by Jackler and Schindler.(12) it was found that cortical mastoidectomy was found to be an effective means of re-pneumatizing the sclerotic mastoid and restoring the hearing and eradicating mastoid sources of infection. Sheehy(13) recommended performing cortical mastoidectomy routinely of all myringoplasty, because it is good practice and because it is better to be safe than sorry. Krishnan after a case series concluded that cortical mastoidectomy does not significantly improve the results in well selected cases.

Role of cortical mastoidectomy in the repair of tympanic membrane perforation and getting dry ear has long been debated. Cortical mastoidectomy was regarded as a means of surgically creating an air reservoir and eradicating sequestered mastoid disease. Yet there is no scientific data indicating that tympanoplasty and cortical mastoidectomy yields better results, but finding of majority of the study are concurrent with present study.

\section{CONCLUSION}

Cortical mastoidectomy gives no statistically significant benefit over simple myringoplasty in the treatment of CSOM (Safe type) as regards to graft success rate and dryness of the ear, when considering the addition of a cortical mastoidectomy to a myringoplasty, the performing surgeon should consider not only the potential benefits but also potential risks and costs to the patient. However, proportional difference in graft take up rate in dry and wet types indicated. The results to be favouring cortical mastoidectomy, especially in wet ears.

\section{REFERENCES}

1. Smyth GD. Tympanic reconstruction. Fifteen year report on tympanoplasty. Part II. J Laryngo Oto 1976;90 (8):713-41.

2. Krishna PH, Devi TS. Clinical study of influence of prognostic factors on the outcome of tympanoplasty surgery. IOSR Journal of Dental and Medical Sciences (IOSR - JDMS) 2013;5(6):41-5.

3. Krishnan A, Reddy EK, Chandrakian C, et al. Tympanoplasty with and without cortical mastoidectomy-a comparative study. Ind J Otolaryngol Head \& Neck Surgery 2002;54(3):195-8. 
4. Kamath MP, Sreedharan S, Rao AR, et al. Success of myringoplasty: our experience. Ind J Otolaryngol Head \& Neck Surgery 2013;65(4):358-62.

5. Mutoh T, Adachi 0 , Tsuji $\mathrm{K}$, et al. Efficacy of mastoidectomy on MRSA-infected chronic otitis media with tympanic membrane perforation. Auris Nasus Larynx 2007;34(1):9-13.

6. Martin MS. Mastoid surgery, in myers otolaryngology head and neck surgery. $2^{\text {nd }}$ ed. Ch 115, Elsevier, ISPN-13 :9781416024453, 2008:7-30.

7. Adunka OF, Buchman CA. Mastoidectomy: otology, neuro-otology and lateral skull base surgery. $1^{\text {st }}$ edition. New York, Thieme, 2011;5:295-6.

8. Lasisi AO, Afolabi OA. Mastoid surgery for chronic ear: a ten year review. The Internet Journal Of Head and Neck Surgery 2008;2(2):13.

9. Chavan SS, Desmukh SD, Pawar VG. Tympanoplasty with or without cortical mastoidectomy. Gujrat Medical Journal 2011;8(1):8-10.
10. Kaur M, Singh B, Verma BS, et al. Comparative evaluation between tympanoplasty alone and tympanoplasty combined with cortical mastoidectomy in non cholesteatomatous chronic suppurative otitis media in patients with sclerotic bone. ISOR-JDMS 2014;13(6): 40-5.

11. Albu S, Trabalzini F, Amadori M. Usefulness of cortical mastoidectomy in myringoplasty. Otology and Neurotology 2012;33(4):604-9.

12. Jackler RK, Schindler RA. Role of the mastoid in tympanic membrane reconstruction. Laryngoscope 1984;94 (4): 495-500.

13. Sheehy JL. Surgery of chronic otitis media. In: English G, ed. Otolaryngology, Revised ed. Vol 1. Philadelphia, Harper and Row, 1985:1-86. 